\title{
GROUNDING AND COMMON GROUND: MODAL PARTICLES AND THEIR TRANSLATION EQUIVALENTS
}

Kerstin Fischer

\section{INTRODUCTION}

In this paper I analyse the functions of German modal particles and their English translation equivalents in order to discuss the relationship between grounding and common ground. I shall proceed as follows. Firstly, I am going to propose that the main function of modal particles is to relate the current utterance to a particular aspect of common ground, namely a proposition 'at hand'. In particular, their main function is to signal one's understanding of what the situation is all about with respect to the argumentative relations built up in the current situation.

Secondly, I am going to illustrate my proposal for the function of German modal particles as lexical markers of common ground on the basis of their English translation equivalents. The hypothesis is that the function of modal particles, to relate the current utterance to the argumentative background of the current situation and thus to indicate what is assumed to be common ground, is usually faithfully translated into the target language English (contrary to previous assumptions). An empirical investigation of data from a translation corpus will show which kinds of functions are translated and what the corresponding markers in English are.

Thirdly, the analysis will subsequently be used to distinguish the linguistic labour of modal particles from other lexical markers of common ground, such as discourse particles. This discussion will lead us into distinguishing between common ground and grounding and between different types of common grounds.

\section{GROUNDINGAND COMMON GROUND}

Situational context is taken here to be something that is not given but which needs to be interactively established. Because it is impossible to pin down objectively what exactly a particular context consists of (e.g. Schegloff, 1997), participants need to signal what they consider the context to be to each other at all 
times. While it may be the case that there are externally given objects, states, or events that are salient to all participants, what the situation consists in depends on the participants' interpretation of these external factors. Context is therefore not external, but jointly established (Schegloff, 1997, Fischer, 2003). The set of assumptions that result from this process, comprising the implicitly and explicitly negotiated as well as the presupposed that the participants take to be shared, is the common ground between the interactans (Clark, 1996).

Two kinds of processes can be distinguished; one has to do with what the speakers say and how they understand each others' contributions, the grounding process (Clark and Schaefer, 1989). Participants display their understanding of each others' utterances and the relationship that holds between these utterances to each other. These interpretations may be ratified or challenged by the coparticipants in the following turn (Sacks et al., 1974). Because speakers are in constant need to signal to each other their understanding of their partners' utterances, the procedures are often implicit. For instance, Clark and Schaefer (1989: 267) list a number of techniques users employ for grounding, most of which are implicit: Continued attention, initiation of the relevant next contribution, acknowledgement (by means of nodding or items like uh-huh or yeah), demonstration, and verbatim display. "These types are grades roughly from the weakest to the strongest" (Clark and Schaefer, 1989: 267), and also from least explicit to most explicit. The result of this process is the conversational record, to use Thomason's (1992) terminology or the dialogue common ground in Fetzer's terms (this volume).

The second major process involved is the signalling of common ground, the speakers' assumptions about what the situation consists in as it is taken to be shared with their communication partners. Like the contents of the utterances which can only be assumed to be sufficiently grounded if they have been ratified by the communication partner, the communicative situation is not objectively given either. Speakers categorize situations on the basis of previous experience and make sense of what they encounter on the basis of personal, social and sociocultural knowledge. Clark (1996) presents a typology of aspects that speakers usually assume to constitute a shared basis, common ground. These aspects of the joint situation are treated as unproblematic, and the participants' displays of their understanding of the situation are usually implicit (see also the criticism of Clark's model in Pickering and Garrod, 2004). As Gumperz $(1982,2001)$ has shown, speakers use these cues to provide their communication partners with indicators as to how their utterances should be understood. That is, speakers display their understanding of the situation as it is necessary for the current utterances to be interpretable. This mechanism has been called framing (Tannen, 
1979). Because of the concurrent nature of such displays, Gumperz has focussed on paralinguistic cues. However, as will be shown here, many different lexical and grammatical means can relate the current utterance to an assumed shared basis and thus function as markers of common ground.

How are grounding and common ground then related? An obvious relation is that by means of grounding what is being said, common ground is being built up. Many researchers thus look at common ground as a set of propositions resulting from the grounding process. However, as I have argued above, situational context is not objectively and independently given, and thus also the speakers' displays of their understanding of the situation contributes to the interactive constitution of the dialogue common ground. As Nemo (this volume) argues, speakers co-define what is business as usual and what is worth attention and how this information should be taken into account with the goal of constituting interlocutive common ground. Moreover, both processes may be managed by the same items, items that can function as discourse as well as as modal particles. In the course of this paper I try to disentangle these two aspects of the joint establishment of the situation further by investigating the role of discourse and modal particles.

Discourse particles, ${ }^{1}$ particularly acknowledgement tokens such as $u h-h u h$, yeah, or okay, serve to provide evidence of understanding to the communication partner. Much recent research has shown how skilfully speakers employ them to provide subtle information about the status of each utterance (cf., most notably, Gardner, 2001, but also Sorjonen, 2001, and Condon and Cech, this volume). What is extremely interesting about them is that they can ground information chunks of very different sizes and types; consider the following uses of yeah:

(1)fmjm_3_03: okay, the third sounds good, and, we can get done, just in time so each of us can go to where we need to go for the evening. uh sounds like a date, how 'bout you, is that good? mdrd_3_04: yeah, it's excellent.

(2)fsma_7_03: well Wednesday I'm busy all day, Tuesday the only time I would have would be at three in the afternoon. flmm_7_04: yeah, I'll be uh I'll be busy on Tuesday from two to four thirty, so, maybe we should make it for next week sometime?

While the first example constitutes an acknowledgement token, accepting the date for the appointment proposed, in the second example, the acknowledgement

I take the term discourse particle to be largely synonymous with the term discourse marker, see Fischer (2005). 
refers only to the successful transmission of the proposal, yet not to its acceptance. Thus, studying feedback is particularly challenging because acknowledgement tokens can contribute to the grounding process on so many different levels.

However, besides directly referring to what is being said, discourse particles may also fulfil other functions, as in the following example:

(3)mdkr_5_01: yeah, Cindy, there's a, couple more things I'd like discuss with you. um can we get together for a couple hours, um this week or next?

In this example, yeah is even the first word in the dialogue, so what it ratifies is the speakers' joint project to sit down and schedule appointments. That is, they also evoke an aspect of the common ground, namely the joint understanding of what the task consists in. Similar uses of the discourse particle okay can be found in Condon and Cech (this volume) who show that okay functions basically in two ways: signalling discourse boundaries and thus indicating agreement about the topic boundaries (the discourse marker use), and acknowledging what is being said (the feedback signal use).

Similarly, Bangerter and Clark (2003) and Bangerter et al. (2003) argue that there are two uses of acknowledgements in conversation. Some markers are used in correspondence with the boundaries of joint projects and some to give feedback within such a project. However, it is important to keep in mind that there are no two separate sets of items that fulfil functions with respect to the ratification of what is being said and with respect to the marking of discourse boundaries. As we have seen above, feedback signals like yeah also refer to a broad range of different types of information (see also Fischer (2005) for a detailed analysis of okay) and fulfil a broad spectrum of functions, such as topic marking, and signalling perception, understanding and acceptance (cf. also Allwood et al., 1992), even though it may fulfil one function more frequently than another. In these tasks discourse particles always refer to the here and now of the communicative situation. In Fischer (2000) I have argued that the functions discourse particles fulfil should therefore be understood with respect to a communicative background frame, explicating the attended to domains relevant in verbal face-to-face interaction.

In addition to the grounding work that discourse particles/ markers may do, contributing to the joint verification of what is being said, their discourse boundary marker use is also related to the activity that the speakers are engaged in, which is not only related to what is being talked about but also about how the 
situation is being understood. Thus, discourse particles not only mark project boundaries but they constitute attempts at jointly establishing of what the current activity consists in. Thus, discourse particles also function with respect to establishing common ground by evoking situational definitions.

We can conclude that the distinction between grounding and common ground is not categorical. Instead, the same items may fulfil functions with respect to both processes, although discourse particles are mostly involved in the grounding process. In the next section we shall see that German modal particles function as framing devices, or contextualisation cues (Gumperz, 1982), providing indirect evidence of what the speaker takes the joint situation to consist in. In this function, modal particles can be distinguished from discourse particles by their reference to the argumentative background of the interaction, which is presented as common ground. In contrast, discourse particles, which are in many cases homophonous with modal particles but which can be distinguished by their occurrence in distinct structural positions, refer to aspects of the here and now of the conversational interaction, including the status of the topic development.

\section{MODAL PARTICLES AS LEXICAL MARKERS OF COMMON GROUNDS}

German modal particles, utterance medial pragmatic particles, such as $j a$, also, aber, and doch, can be described by means of the following attributes: They are more typical of spoken than of written language (Thurmair, 1989); unlike discourse particles, such as English oh, yes, okay and well, they are intonationally integrated and occur inside sentence boundaries where their occurrence is restricted to particular syntactic positions (in particular, in the syntactic middle field (Abraham, 1991b)). Furthermore, modal particles are restricted to certain sentence types; for instance, the German modal particle $j a$, which in its discourse particle uses is often equivalent to English yes, may occur in assertions but not in questions. The meanings of modal particles do not modify particular segments but refer to the whole utterance (Lindner, 1991: 166). The meanings of modal particles are furthermore not truth-functional but indispensible for the "felicity conditions" of an utterance (Abraham, 1991a: 5). Their meanings are also considered to be syncategorematic (e.g. König and Stark, 1991), or to have at least a highly abstract semantic content (Lindner, 1991). Finally, many modal particles have a stressed and an unstressed variant whose interpretations are different, and they all have 'homonyms' in other word classes, such as discourse particles, conjunctions, and adverbs. ${ }^{2}$

\footnotetext{
Some researchers exclude the stressed variants from their analyses, for instance,
} 
Modal particles have been proposed to fulfil a number of different functions in dialogues; thus they have been suggested to be illocutionary indicators (Helbig, 1977: 34, Kawashima, 1989: 281). They have also been argued to divide a sentence in given and new information (Krivonosov, 1989: 33-35) and to establish coherence (König and Requardt, 1991). Gelhaus (1995: 371) furthermore proposes that they express speaker attitude (see also Nehls, 1989: 283, Doherty, 1985). Regarding Swedish modal particles, Aijmer (1997) argues that they express epistemic modality. More generally, modal particles have been suggested to anchor an utterance in the communicative interaction (Thurmair, 1989: 2, Helbig and Buscha, 1986: 476), and their indexical nature has often been pointed out (see also Fillmore, 1984, Petric, 1995, Waltereit, 2001).

Developing further an account of German modal particles that has been proposed first by Diewald and Fischer (1998) and further detailed in Diewald (2005) and Fischer $(2000,2005)$, the starting point in this investigation is also the indexical structure of modal particles. The assumption made here is that the general grammatical function of modal particles is to connect the current utterance to a pragmatic pretext, i.e. to a proposition 'at hand' which is part of the non-verbal argumentative context. In this model, the readings of a modal particle are created by interaction of the invariant meaning of the respective lexical item, the current utterance, and the element indexed: the pragmatic, argumentative, pretext. I take it that speakers need to display to each other in which ways their current utterances relate to the argumentative situation (Ducrot, 1996, see also Nemo, this volume, and Nyan, this volume). That is, with argumentation theory I hold that language is inherently dialogical and that every utterance contains several other 'voices' that correspond to that part of the common ground that constitutes the argumentative background of each utterance. The assumed background needs to be conveyed to the recipient, as Nyan (this volume) puts it: "initiating decisionmaking in others crucially depends on getting them to view the situation of reference as a member of a category of initial situations to which a category of response-options is paired." One means to refer implicitly to aspects of the argumentative background, the situation 'at hand', are, I argue, German modal particles. The grammatical function specific to modal particles is thus to relate the current utterance to an aspect of the argumentative common ground, that is, to a propositional aspect of the communicative situation which has not necessarily

Hentschel (1986). However, her description the function of stressed doch (1986: 128) corresponds directly to the definition of modal particles employed here, and it is compatible to her own (1986: 2-3, cf. also Weydt, 1986: 401). I conclude that both stressed and unstressed variants need to be considered as modal particles (see also Diewald and Fischer, 1998). 
been verbalised, but that is proposed to be shared. The semantic content of each modal particle lexeme specifies the relation as, for instance, additive or adversative. A schematic description of the meanings of modal particles, which represents the relationship between an utterance containing the modal particle and a pragmatic pretext, is the following:

$$
\text { common ground [pragmatic pretext: P]\& modal particle (utterance, } \mathrm{P} \text { ) }
$$

The modal particle thus relates the current utterance to an aspect of the common ground, the pragmatic pretext. This function can be illustrated regarding the following example which constitutes the answer to a suggestion to meet as early as seven o'clock in the morning: ${ }^{3}$

Natürlich, ich werde aber erst ab neun Uhr da sein.

'I certainly won't be there before nine o'clock.'

Aber expresses an adversative relation between the pragmatic pretext and the relevant situation. The pragmatic pretext, the contextual assumption that is taken to be shared by the participants, is thus the negation of the situation described in the current utterance:

(6) pragmatic pretext: at hand: meet before $9 \mathrm{am}$

relevant situation: I won't be there before 9 am

$\rightarrow$ utterance

ich werde aber erst ab neun Uhr

da sein

The grammatical function, to relate the current utterance, here, that the speaker will not be there before nine, to an aspect of the situation at hand, namely to meet before nine, is fulfilled by all modal particles, while the respective modal particle lexemes, here aber, specify the relation between pragmatic pretext and the utterance in which they occur, which is in this case adversative. The modal particle aber can thus be seen as an instruction to retrieve (or construe) a pragmatic pretext which is "a logical variant" (Foolen, 1989) of what is being said, in this case its opposite.

The pragmatic function which results from the grammatical function to relate the utterance containing the modal particle to the contextual situation, or, more specifically, to the pragmatic pretext, is to mark an utterance as non-initial, i.e. as

3 The examples are from a corpus of German appointment scheduling dialogues which were translated into English. The corpus will be described in more detail in section 4. 
a natural consequence of the communicative situation. At the same time the speaker's own contribution is played down, and hence possibly offensive acts become less face-threatening (Brown and Levinson, 1987). The main pragmatic function of modal particles is thus interpersonal (see also Weydt, 2005, Fischer, 2005), or, as Nemo (this volume) puts it, it is justificational. However, this interpersonal function does not exclude functions on other levels of discourse; like discourse particles, modal particles can fulfil several functions at the same time (Fischer, 2000), but they do so in virtue of their grammatical function to relate the current utterance to the argumentative context.

While in the previous example the proposition indexed by means of the modal particle had just been at issue, modal particles may also refer to what the current speaker assumes to be part of the situation 'at hand' on the basis of previously discussed information. For instance, in example (7), by using the modal particle doch the speaker indexes a proposition that suggests that the meeting should not be postponed to the next week:

\section{(7) ich denke wir sollten das Ganze dann doch auf die nächste Woche verschieben. \\ 'I think we should rather postpone the whole matteruntil next week.'}

Stressed doch has the same function as modal aber: it refers to a proposition 'at hand' that does not correspond to the situation expressed. This proposition is claimed to be accessible to both, it is claimed to be common ground (cf. Pittner, this volume). In fact, in this dialogue it has been uttered by one of the speakers several turns before. Thus, in this example, the pragmatic pretext, the proposition 'at hand', is part of the common ground because it is part of the interactionally grounded dialogue history. However, the pragmatic pretext need not have been mentioned at all. There are also uses of modal particles that do not refer to anything that has been previously said, but to a proposition that is assumed to be held by both communication partners. This is the case for supposedly perceptually available aspects of the shared context and for evaluations that are taken to be shared. For instance, in the following example, the modal particle aber is used to refer to an assumption that has not been talked about before, that the task (to construct a toy airplane) is actually quite complicated (although it is a children's toy): ${ }^{4}$

$$
\text { ja. oh, das ist aber schwierig. }
$$

4 This example stems from the toy airplane construction dialogues recorded in the framework of the SFB 360 in Bielefeld (Sagerer et al., 1995, cf. Diewald and Fischer, 1998). The translation is mine. 
'yes. oh this is difficult after all'.

That is, the use of modal aber proposes that there is a shared evaluation of the task as not difficult 'at hand'. Modal particles thus indicate a particular proposition that is claimed to be part of the argumentative context. Common ground is therefore not a fixed set of propositions previously established, but a definition of the situation that is interactively negotiated (see Nemo, this volume, Fetzer, this volume). Modal particles contribute to the negotiation process by indicating such propositions. At the same time, they present an utterance as argumentally related to the supposedly shared situation.

An aspect currently under discussion is the question whether there should be a single invariant meaning for each particle or whether a number of different senses should be assumed. König (1997: 59), for instance, criticises that the search for a common meaning is often given up too easily in favour of a polysemic approach. Also Thurmair (1989) and Abraham (1991) argue for a minimalist approach, which assumes as few distinct readings for each particle as possible. Waltereit (2001: 1414), however, refuses such an account because in his view it has to be traded against very abstract meaning descriptions. This may indeed be true, which is however not problematic in itself. For instance, no one would object if the meaning description of, say, the topicalisation construction would be abstract. The point is instead to provide accounts that are concrete enough to allow the prediction of an interpretation of the respective particle in context. While the morphemic meaning may indeed be an abstract but invariant factor in the interpretation of a modal particle, it may not be the only one. The structural position, i.e. the construction in which a morpheme is employed, may contribute further information that allows the interpretation of each particle in its respective context (see also Fischer, 2000, 2005). In our case, tied to the grammatical function of modal particles, there is a particular interpretative mechanism, which is coded in the construction in which the respective morpheme occurs. The morphemic meaning of each particle is indeed taken to be the same for its occurrences as modal particle, as well as as adverb, conjunction, or discourse particle, or whatever 'homonyms' in other word classes the modal particle may have. However, the invariant meaning tied to a particular lexical item interacts with the constructional meaning of its particular use, for instance, as a modal or discourse particle, in a certain structural context (see Fischer, 2005). The approach presented is thus minimalistic such that an invariant meaning accounts for the relationship between the different readings of a modal particle, as well as between these and uses of the same morpheme in other word classes. It is however specific enough to account for particular occurrences because of the interpretative contribution of the respective construcions. 
Another important issue in models of modal particles is the role of context. As mentioned above, most approaches hold that modal particles are syncategorematic and thus get their interpretations from the contexts in which they occur, and that they relate in some way or other to the communicative situation. There are, however, different ways of invoking context. Waltereit (2001) presents a recent approach that makes use of the notion of context. His approach is speech-act theoretic such that modal particles are taken to encode information on the preparatory conditions of speech acts by calling up particular situations that are metonymically related to the non-modal counterparts of each modal particle. The mechanism involved may however be very different for different modal particles. For instance, for modal $j a$, the situation called up is one in which, during an interaction of several turns, the hearer has already agreed on a proposition by using ja as an answer signal (2001:1413). In contrast, the French particle quand-même points to a situation in which real-world norms hold (2001: 1403f), and the diminutive in Italian points to non-serious situations, such as talking to children (2001: 1409-1410). In Waltereit's model, the common basis of modal particles is thus that they all point to particular situations, which are related by contiguity to the use of their non-modal counterparts. The result is a polysemic approach. This could also mean giving up the search for a common meaning too easily. Furthermore, the heterogeneity of the situations proposed to be involved in the meanings of modal particles indicates the danger of limited predictability and thus restricted learnability of the mechanism proposed.

Another way of making use of context in the description of modal particles is to claim that they refer to contextual assumptions. König (1997) proposes a relevance-theoretic approach, which is basically along similar lines to the approach outlined here: the modal particle refers to a contextually available proposition. However, relevance theory suffers from the fact that it does not provide a way for identifying the contextual propositions that are 'relevant' (Nemo, 1988). There is no independent evaluation of the 'processing costs', which, according to relevance theory, speakers try to avoid by maximising the informational value available at the same time (Sperber and Wilson, 1986). The selection of contextual propositions is, however, completely open in relevance theory, and thus the criticism Wierzbicka (1992) applied to prototype theory, namely that prototypes are used to save descriptions that make predictions that are too narrow or even wrong, can be applied similarly to relevance theoretic accounts of modal particles regarding the notion of context. In contrast, our approach as proposed here states directly what the pragmatic pretext is - it consists of the proposition expressed in the current utterance minus the contribution of the particle morpheme. The model proposed here is thus not a 
'context saves' model, but allows a principled way to investigate how speakers make use of, and negotiate at the same time, aspects of common ground.

\section{CORPUS}

In the following, occurrences of German modal particles and their translations will be analysed, first in order to illustrate the model proposed, and second to identify a set of lexical markers of common ground for English. Since these items serve as translation equivalents for German modal particles, they will, if the model proposed here is correct, also function to relate the current utterance to the argumentative background which is assumed to be common ground by the participants.

Three German appointment scheduling dialogues recorded in the Verbmobil project (Wahlster, 2000), for which there are five English translations (by professional translators and students of translation), serve as the data set for this investigation. The translators, who are all, with the exception of d), native speakers of German, which is the source language in this corpus, were the following:

a) graduate student of translation studies

b) Dipl.-Fachübersetzerin (professional translator)

c) graduate student of translation studies, exam candidate

d) lecturer, native speaker of English

e) undergraduate student of translation studies

All five translations will be considered in order to get an overview of different translation possibilities, even though the translations e) have been created by an undergraduate student who still makes mistakes with respect to the target language. The translations were carried out on the basis of the original spoken dialogues to which the translators could listen as often as they liked. They produced written translations of the original taped speech in the three dialogues. The transcriptions are based on the whole dialogues, not on single turns, and thus the translators and interpeters were involved in a 'holistic enterprise' (O'Sullivan and Rösler, 1989).

\section{ENGLISH EQUIVALENTS TO GERMAN MODAL PARTICLES}


Previous contrastive approaches have analysed which lexical and grammatical correspondents modal particles may have; for instance, conjunctions, adverbs, formulaic expressions, auxiliary verbs, and tag questions have been found to be functional equivalents (e.g. Fillmore, 1984, Nehls, 1989, Abraham, 1991b: 206, Fischer and Drescher, 1996: 855-856), that is, to have "essentially the same pragmatic conditions" (Fillmore, 1984: 133). König and Stark (1991: 304), in a lexicological approach to modal particles, argue that "equivalence often has to be established on the level of the next larger unit, the phrase, the clause, or the whole sentence." However, in studies which also consider the distribution and use of modal particles, most often no equivalents were identified at all (Fillmore, 1984, O'Sullivan and Rösler, 1989, Abraham, 1991a: 2, Fischer and Drescher, 1996); Fillmore (1984:133), for instance, argues about the translation equivalents of German modal particles that "these expressions, if used in English as often as their counterparts are used in German, would produce very mannered speech."

There may be, in principle, two reasons for this observation. One reason may be that German speakers attend to meanings or functions to which speakers of other languages such as English do not attend; that is, German modal particles may express something that other languages do not express. This opinion is held, for instance, by Fillmore who explains the differences between the two languages as a matter of 'larger' pragmatic practices, such that it is a "'large' pragmatic fact about German (...) that the colloquial language welcomes (one may almost say 'requires') pragmatic particles that reflect choices in which individual utterances can be situated in their discourse context. (...) the corresponding forms in English cannot be grammatically incorporated into surface clauses" (Fillmore, 1984:133). The difference is attributed to a different level of formal complexity: "This difference seems to exist by virtue of the fact that the German forms are 'particles' while the English forms are 'formulas'" (1984:133-134). Some lines below Fillmore adds a second reason for the different distribution of particles and their proposed functional equivalents: "The description of these 'larger' patterns of use appears to me to be about as difficult to come by as a description of the two cultures" (1984:134). Eventually, however, he leaves open what these 'larger' facts are. Similarly, O'Sullivan and Rösler (1989) argue that in the translation of English texts into German the use of modal particles should be seen as a holistic enterprise depending on the text type. However, they do not explain what the properties of the respective text types are which make the use of modal particles relevant, and what is so special about German conversation in contrast to English conversation.

A more likely reason for the fact that often no translation equivalents have been found could be that it was not clear what the functions of modal particles actually 
are; none of these previous contrastive approaches described above has started out from a concept of what the grammatical function of the word class modal particle is or what general pragmatic function they actually express. Instead, their search for translation equivalents was guided by local decisions on the current pragmatic function of each modal particle occurrence. This procedure often yields no correspondents at all. However, an attempt to find functional equivalents in another language may be successful if we investigate a more general level than the actual functional interpretation of a modal particle occurrence in a given context. Thus, the determination of translation equivalents may be more successful on the basis of a thorough functional analysis of the grammatical function of the word class. Results from such a functional analysis are also necessary in order to explain what the "larger" pragmatic facts are that determine different distributions in the two languages, if there are any. Therefore the procedure in this investigation is to reanalyse the pragmatic functions of modal particles and thus to pave the ground for a new analysis of their translation equivalents. ${ }^{5}$

The translation of modal particles into languages that do not have a comparable set of modal particles, such as English (but see, for instance, Aijmer, 1997), allows us to identify a number of other types of linguistic strategies that fulfil the same function. Although it has frequently been argued that no translation equivalents can be found, at least not to a comparable amount (Nehls, 1989, Fillmore, 1991), in particular the function of modal particles to relate the current utterance to the common ground can usually be found in the translation. That is, if the translation is based not only on individual utterances, but also on the argumentative context, the general grammatical function of modal particles can be demonstrated to be present also in the English target.

For the grammatical function of modal particles, of relating the current utterance to the assumed argumentative common ground, it is usually possible to find translation equivalents in the translated dialogue. The relationship between pragmatic pretext and current utterance in English is not only expressed by particular lexical or grammatical means but by the interaction of a large number

5 It has also been proposed that the linguistic work done by modal particles in German is done by prosody in English (Schubiger, 1965). Prosody indeed has been found to be used as a contextualization cue, i.e. to fulfil the function proposed for modal particles in this article (Gumperz, 1992, 2001). However, prosody selfevidently also fulfils this function in German (e.g. Krivonosov, 1963: 62). It is therefore taken to be a justified procedure here to concentrate on the lexical and grammatical correspondents of German modal particles which are visible in the transcripts. 
of factors, several alternatives being possible; for instance, in the example of doch below, discussed in part as example (7) above, we find a number of different possibilities:

(9)Dienstags um 10 ist bei mir jetzt wiederum schlecht, weil ich da noch trainieren bin. Ich denke wir sollten das Ganze dann doch auf die nächste Woche verschieben. Geht's bei Ihnen da?

With the current utterance the speaker suggests postponing the appointment to the following week. This is in contrast to his partner's earlier proposal to meet in the current week, but it turned out that no date could be found without sacrifices on either side. The implicit pragmatic pretext is here that the communication partner would prefer not to postpone the meeting. The speaker now uses doch to relate the current proposal to the pragmatic pretext, i.e. the implicit proposition not to postpone the appointment, stressed doch signalling a relationship of contrast. This is rendered by the translators in the following ways: ${ }^{6}$

a) Tuesday at 10 doesn't suit me, at that time I'll still be, em, doing sports. I think we'd better postpone the meeting till the week after. Does that suit you?

b) Tuesday ten o'clock is bad with myself, since I'm still at my sports training then. I think we should put it off until the following week. Would that be fine with you?

c) Tuesday at ten is bad on mypart since I will be training then. I think we should rather postpone the whole matter until next week. Is that okay with you?

d) Tuesdays at ten is inconvenient for me on the other hand because I am still off training. I think in that case we should postpone the whole thing to the week after. Would that be all right with you?

e) On Tuesday at ten it would be difficult for me because I still will be training then. In this case I think we should postpone our date to next week. Would that be all right with you?

While translation b) does not reflect the function of the modal particle doch at all, the translator of a) uses better, which is relational and, like the modal particle doch, compares the current to the previous proposal. In c) we find the relational item rather discussed above. The translator of $\mathrm{d}$ ), who is a native speaker of English, renders the relational structure firstly by means of on the other hand (although there has been no on the one hand), and secondly by in that case, thus

$6 \quad$ I have marked the proposed correspondents of the function of modal particles to relate the current utterance to the argumentative common ground in italics. 
implying a relevant alternative which is in contrast with the current proposal. Likewise, translation e) uses in this case to refer to the pragmatic pretext.

Thus, several of the translation variants activate the propositions 'at hand' while they do not necessarily signal the relationship between the current utterance and the argumentative common ground. Thus, rarely is a relationship specified that would be as strong as the adversative relationship indicated by German doch. Whereas the content of the modal particle lexeme itself is reduced to a weak opposition between two alternatives, one of which is implicit, the grammatical function of the modal particle doch is translated into the target language in most cases.

In the following example of German doch, whose interpretation in this utterance can be paraphrased as "contrary to our previous idea to meet later in the day," its lexical meaning is again not transferred into the target language. Instead, we find better in translations a) and d), then in c), and in a) and e) the other hypothetical situation is referred to by means of the subjunctive mood; thus, as in the previous example of doch above, it is the relational structure that is particularly translated into English. That is, while the pragmatic pretext is called up as in the German source, the relationship between pragmatic pretext and current utterance, which is contrastive in German, is not specified in the same way in English.

(10) Sie haben recht, das wird etwas knapp. Sollten wir vielleicht doch gleich um 10 Uhr anfangen?

a) Well, you're right. We might not have enough time. Do you think it's better to start at 10 o'clock sharp?

b) You are right - it's a bit tight - should we start right at ten?

c) You're right. We'll be short of time then. Maybe we should start right at ten o'clock.

d) You are right, that is a bit too short. It would be better to start at 10 .

e) You are right. This would be a bit short. May be we should already start at 10 ?

The analysis is thus:

(11) pragmatic pretext: at hand: we should start later than $10 \mathrm{am}$

relevant situation: we should start right at 10am

$->$ utterance

Sollten wir vielleicht doch gleich

um 10 Uhr anfangen? 
In the next example, the speaker reacts to the partner's proposal to consider a particular week by stating his availability during this week which is restricted to Friday. That is, the work done by the utterance containing allerdings is to state (preliminary) acceptance of the previous proposal but to formulate a restriction: 'given that we take this week, I have got the following problem: I can only meet you on Friday'.

$\begin{array}{ll}\text { pragmatic pretext: } & \text { at hand: we meet this week } \\ \text { relevant situation: } & \begin{array}{l}\text { in this week I only have time on } \\ \text { Friday } \\ \text { da ging es bei mir allerdings nur } \\ \text { am Freitag }\end{array}\end{array}$

In the translations, translation b) represents this relation between the current utterance and the proposal made by the communication partner; the work then is doing is very similar to the work done by allerdings: 'if we take this week, then I'll have the following problem: I can only meet you Friday'. Similar work is done by the subjunctive mood in translation a): 'if we decide for this week, then only Friday would be possible' (cf. Aijmer, 1997). In translation c) the proposal to meet next week, which constitutes the pragmatic pretext of the utterance, is referred to by means of next week. Both d) and e) use unfortunately which is not relational; instead, translations d) and e) express an evaluation, thus showing that the speaker does not reject the partner's proposal thoughtlessly or without good reason; the translators of d) and e) have thus chosen to express the interactive consequences the restriction to Friday may have:

(13) Da ging es bei mir allerdings nur am Freitag, da ich die ganze Woche über noch in Washington bin. Wie sieht's am Freitag aus?

a) It would only be possible on Friday since I'll be in Washington the rest of the week. What about Friday?

b) Then, only Friday would be free, since I'll be in Washington for the whole week. What about Friday?

c) The only day I'm free next week is Friday. I'm spending the remainder of the week in Washington. How about Friday then?

d) Unfortunately I am only free on Friday that week because I am in Washington the whole week. What about Friday?

e) Unfortunately only on Friday because I still will be in Washington on 


\section{Thursday. What about Friday?}

Thus, there are a number of choices for translating the function fulfilled by the German modal particle.

There are, however, also examples of modal particles whose translation is more difficult to recognise than has been the case with the previous examples because of redundant coding of the same function, as, for instance, in the following example of denn:

(14) Ja, Frau Petz, dann lassen Sie uns doch einen Termin ausmachen. Wann wäre es Ihnen denn recht?

a) Well, Mrs Petz, then let's fix an appointment. When would it suit you?

b) Well, Ms./Frau Petz; then let us fix a date. When would you like to meet?

c) Let's make an appointment, Frau Petz. When would it suit you best?

d) Good, Frau Petz, let's arrange a time then. When would it suit you?

e) Yes, Mrs Petz, then let's make a date yet. When would you like it?

The function of denn is to relate the questioning act to the communicative situation. As a conjunction, denn is consecutive. Here, it serves to indicate that the current utterance follows as a consequence from the situation. This is similar to and-prefacing in interview situations; Heritage and Sorjonen (1994) show how the use of and-prefacing by a nurse may present her possibly face-threatening questions as based on a list of questions for which she is not responsible. By presenting the questions as non-initial, the force of the questions can therefore be reduced. Similarly, the modal particle denn in the example here, which constitutes a request to propose a time and as such a possibly face-threatening act (Brown and Levinson, 1987), serves to maintain the interpersonal relationship between the speakers by presenting the utterance as a consequence of the situation. In particular, the claim is that asking the question itself has already been part of the common ground, it has been at hand already.

The subjunctive mood in the German source text may be argued to fulfil the same face-preserving function in a different way; thus, while there are no particular correspondents for denn in the translations, the reason may be that subjunctive 
mood and modal particle redundantly code the same pragmatic information, indicating something like "if I was allowed to ask, I would ask:". Thus only one of these means is transferred into the target utterance; note that all five translations use the subjunctive.

pragmatic pretext: at hand: if I may ask: when would it suit you?

relevant situation: I ask: when would it suit you?

-> utterance

Wann wäre es Ihnen denn recht?

In another example of denn, two translators employ then, which corresponds to the consecutive meaning of denn as a conjunction. Interestingly, one translator firstly signals agreement before she continues with the proposal:

(16) Wie wär's denn um dreiviertel elf?

a) What about a quarter to 11 ?

b) How about a quarter to eleven then?

c) Okay. How about a quarter to eleven.

d) How about a quarter to eleven

e) Yes, what about 10.45 then?

Thus, even denn in questions can be shown to be realised in several English translations.

Returning to example (14) above, I would like to argue that similarly the relationship to the pragmatic pre-text, whether this is the moment to sit down and schedule appointments, expressed by unstressed doch in example (14) is redundantly coded by dann, which is consistently translated by then, and by the initial discourse particle $j a$, rendered as yes, well and even as good by the translators. In this case, the initial discourse particle $j a$ has the same function as the discourse particle yeah in example (3). That is, the contribution of modal doch here is very similar to the other two devices, namely to refer to the participants' willingness to sit down and to schedule appointments, since this is the argumentative background of the beginning of this dialogue. Similarly, in the next example of unstressed doch, of which we unfortunately only have two translations, one translator refers to the pragmatic pretext indexed by means of as far as I remember, while the other one includes before as a time index for a previous conversation: 
(17) Guten Tag Herr Müller, wir hatten uns doch schon gesprochen und uns einen Termin Ende April Anfang Mai ausgedacht. Hatten Sie da Zeit?

a) Hello, Mr Müller. As far as I remember we have already talked and arranged an appointment for the end of April or beginning of May. Would that suit you?

c) Hello Herr Müller we have talked on the phone before and have made an appointment for the end of April or the beginning of May. Would that suit you?

Another example is the modal particle also, which is by most translators rendered by means of then, presenting the current utterance as a consequence of the argumentative situation. One translator, however, employs the phrase to recap to account for the meaning of also, thus indicating how the modal particle refers to the whole topic, as it was discussed in connection with discourse particles at the beginning of this paper:

(18) Schön dann machen wir's so. Das war also Freitag, 23. Oktober, 14 Uhr 45. Alles klar. Bis dann. Tschüss.

a) Okay, then we'll meet on Friday, 23rd of October, 2.45 pm. See you then, good_bye.

b) O.K. We'll do it this way. Then it is Friday the twenty-third of October two fourty-five p.m.; all right; see you; bye.

c) Okay let's do it like this. It's Friday, 23rd October, at a quarter to three then. Alright. See you. Bye.

d) Right that's it then, to recap Friday 23rd of October at a quarter to three. Got it, see you then, bye

e) Well, we make it this way. On Friday, the 23rd of October at 2.45. Everything okay. See you then. Bye.

We can thus identify an interesting overlap between discourse particles and modal particles here. While discourse particles can refer to the thematic organisation of the dialogue because it is part of the current ongoing activity, modal particles may refer to the topic structure because it is part of the shared argumentative background. Thus, without having to give up the functional descriptions of discourse and modal particles respectively, we can account for the functional equivalence of the two types of particles with respect to thematic organisation.

To sum up, for some modal particles, their lexical content was not always found 
to be translated, whereas their relational structure with reference to the pragmatic pretext was usually transferred into the target language. Regarding the translators, although these few examples of no more than five translators are admittedly too few to allow reliable conclusions, some differences became apparent. While especially the native speaker of English translated the German modal particles occurring by means of rendering the relational structure proposed for modal particles, the professional German translators translated the relational structure of modal particles less often. It may be speculated that, resulting from the fact that previously the function of modal particles to relate the current utterance to the pragmatic situation at hand had not been identified and thus was not reported to students of translation, the missing translation equivalents in the professional translators' translations are actually an artefact of their training. In any case it can be concluded that it is not a ("larger") fact about English that it would be lacking a certain pragmatic function that is fulfilled by modal particles in German, but that its expression had just not been realised.

\section{PRAGMATIC MARKERS AND THE RELATIONSHIP BETWEEN GROUNDINGAND COMMON GROUND}

The results from this investigation show that the hypothesis that there is a relational semantic basis and grammatical function of modal particles which explains their pragmatic functions is supported by the contrastive analyses; especially their relational structure is rendered in the target language by a number of different lexical items and grammatical constructions which all share the same relational structure. Contrary to discourse particles, which are intimately connected to the hereand now of the actual communicative process, including the current activity in which the speakers are involved, modal particles refer to one particular aspect of the situation: to a proposition that constitutes part of the argumentative background of the current utterance and which is taken to be shared by the communication partners. Particularly contrastive modal particles usually evoke alternative situations, other 'voices' that are 'at hand', that serve as implicit shared background for the current discussion. Many English translation equivalents indicate such alternative situations, e.g. the use of the subjunctive and relational items, like better, rather, or on the other hand. While discourse particles thus contribute to establishing the current situation, a big part of which is what is being said, and thus mostly contribute to the grounding process, modal particles claim to refer to 'voices' that are implicitly part of the assumed common ground. They therefore also contribute to the grounding of the situation, by evoking propositions that (are claimed to) exist as shared background, but which 
in fact constitute interpretations of what the situation consists in. In this respect it may be argued that modal particles "update common ground" as Pittner (this volume) claims. ${ }^{7}$ The process of grounding and the evoking of common ground are thus highly interrelated and co-dependent. Within this continuum however discourse and modal particles are located differently with respect to different kinds of information activated, an overlap however occurring with respect to the thematic structure which can be referred to by both kinds of particles.

Another result of this investigation is that only a hypothesis about the general function of modal particles allows us to identify the translation equivalents of German modal particles. Thus, not only the relational hypothesis can be verified in this contrastive study, but also several ways by which the function of indicating aspects of common ground may be realized in English could be determined. Candidates for translation equivalents are, for instance, adverbs, such as unfortunately and really, but more often relational concepts, ${ }^{8}$ such as better, rather, in that case, and even subjunctive mood. Does this mean that all these devices have to be considered as lexical markers of common ground, indicating what the speaker considers to be the context of her utterance? Do our results lead to an inflation of the concept of lexical markers of common ground?

Our hypothesis was that speakers in interaction need to signal to each other what they consider as the argumentative background of the interaction, and it was proposed that in German this may be done by means of modal particles. If this constitutes however a general need of the participants in interaction, English should equally have devices to fulfil this function. Besides extensive literature on the grounding process, which is concerned with the creation of common ground, not much is known about how speakers make their perspective on this common ground available to each other. One influential study is Tannen (1979) who identifies 16 different surface cues that allow her to infer the contents of the background information that speakers draw upon in their narratives, for instance negation, generalisation, moral judgement, repetition, false starts, backtracking, hedging and so on. In this paper, a closer look at two such devices has been taken: discourse and modal particles. For discourse particles it was found that they contribute to common ground as acknowledgements of what is being perceived, understood, and accepted and as indicators of the status of the current

7 However, the notion of updating presupposes that common ground has been different before, which may or may not be true, depending on the respective modal particle. I would therefore propose to restrict the suggestion to a contribution to the situational definition.

8 See also Okada, this volume, who claims all deictic items to function as lexical markers of common ground. 
activity. They thus serve in establishing a joint perspective on the current communicative situation. Modal particles, in contrast, refer to the argumentative common ground. Speakers present their information as contributions to larger argumentative activities, such as contrasting, supporting, evidencing, etc. and these rhetorical relations are indicated by means of modal particles. Thus, modal particles are framing devices par excellence, indicating the current activity, but as their translation equivalents in English have shown, they are by far not the only means to do so. Modal particles are grammaticalised means to refer to the argumentative common ground, as much as feedback signals are grammaticalised means to ground utterances. However, as we have seen, many other means may be used as lexical markers of common grounds.

\section{REFERENCES}

Abraham, Werner, 1991a. "Introduction". In: W. Abraham (ed.), Discourse Particles: Descriptive and Theoretical Investigations on the Logical, Syntactic, and Pragmatic Properties of Discourse Particles in German. Benjamins, Amsterdam, 1-10.

Abraham, Werner, 1991b. "Discourse particles in German: How does their illocutionary force come about?" In: W. Abraham (ed.), Discourse Particles: Descriptive and Theoretical Investigations on the Logical, Syntactic, and Pragmatic Properties of Discourse Particles in German. Benjamins, Amsterdam, 203-252.

Aijmer, Karin, 1997. "I think" -- an English modal particle. In: Toril Swan and Olaf Jansen Westvik (eds.), Modality in Germanic Languages: Historical and Comparative Perspectives. Mouton de Gruyter, Berlin, 1-47.

Allwood, Jens, Nivre, Joachim and Ahlsén, Elisabeth, 1992. On the Semantics and Pragmatics of Linguistic Feedback. Journal of Semantics 9, 1-26.

Bangerter, Adrian, and Clark, Herbert H., 2003. Navigating joint projects with dialogue. Cognitive Science 27, 195-225.

Bangerter, Adrian, Clark, Herbert H. and Katz, Anna R., 2004. Navigating joint projects in telephone conversations. Discourse Processes 37, 1-23.

Brown, Penelope and Levinson, Stephen, 1987. Politeness. Some Universals in Language Usage. $2^{\text {nd }}$ edition. Cambridge University Press, Cambridge.

Clark, Herbert H., 1996. Using Language. Cambridge University Press, Cambridge.

Clark, Herbert H., Wilkes-Gibbs, Deanna, 1986. Referring as a collaborative process. Cognition 22, 1-39.

Clark, Herbert H. and Schaefer, Edward R., 1989. Contributing to discourse. 
Cognitive Science 13, 259-294.

Condon, Sherri and Cech, Claude, this volume. Ok, next one: Discourse markers of common ground.

Diewald, Gabriele, 2005. Discourse particles and modal particles as grammatical elements. In: Fischer, K. (ed.), Approaches to Discourse Particles. Elsevier, Amsterdam.

Diewald, Gabriele, Fischer, Kerstin, 1998. "Zur diskursiven und modalen Funktion der Partikeln aber, auch, doch und ja in Instruktionsdialogen". Linguistica 38, 1, 75-99.

Doherty, Monika, 1985. Epistemische Bedeutung [Studia Grammatica 23]. Berlin: Akademie-Verlag.

Ducrot, Oswald, 1996. Slowenian Lectures/Conférences Slovènes. Edited by Igor Zagar, ISH, Ljubljana.

Fillmore, Charles J., 1984. "Remarks on contrastive pragmatics". In: J. Fisiak (ed.), Contrastive Linguistics: Prospects and Problems [Trends in Linguistics: Studies and Monographs 22]. Mouton, Berlin etc., 119-141.

Fillmore, Charles J., 1981. Pragmatics and the Description of Discourse. In: Cole, Peter (ed.), Radical Pragmatics. Academic Press, New York.

Fischer, Kerstin, 2000. From Cognitive Semantics to Lexical Pragmatics. The Functional Polysemy of Discourse Particles. Mouton de Gruyter, Berlin, New York.

Fischer, Kerstin, 2003. Notes on Analysing Context. In: Kühnlein, Peter; Rieser, Hannes and Zeevat, Henk (eds.), Perspectives on Dialogue in the New Millennium. John Benjamins, Amsterdam and Philadelphia.

Fischer, Kerstin, 2005. Frames, constructions and morphemic meanings: The functional polysemy of discourse particles. In: Fischer, K. (ed.), Approaches to Discourse Particles. Elsevier, Amsterdam.

Fischer, Kerstin, Drescher, Martina, 1996. Methods for the description of discourse particles. Language Sciences 18 3-4, 853-861.

Foolen, Ad, 1989. Beschreibungsebenen für Partikelbedeutungen. In: Weydt, Harald (ed.), Sprechen mit Partikeln. Berlin, 305-317.

Gardner, Ron, 2001. When Listeners Talk. Pragmatics \& Beyond New Series 92, John Benjamins, Amsterdam.

Gelhaus, Hermann, 1995. "Die Wortarten". In G. Drosdowski et al. (eds.), Duden: Grammatik der deutschen Gegenwartssprache. 5., völlig neu bearbeitete und erweiterte Auflage. Dudenverlag, Mannheim etc., 85-398.

Gumperz, John, 1982. Discourse Strategies. Cambridge University Press, Cambridge.

Gumperz, John, 2001. A discussion with John J. Gumperz. Carlo L. Prevignano and Aldo di Luzio. In: Eerdmans, Susan L., Prevignano, Carlo L. and Thibault, Paul J. (eds.): Discussing Conversation Analysis. Benjamins, 
Amsterdam, Philadelphia.

Helbig, Gerhard, 1977. Partikeln als illokutive Indikatoren im Dialog. Deutsch als Fremdsprache 14, 30-44.

Helbig, Gerhard, Buscha, Joachim 1986. Deutsche Grammatik. Leipzig: Verlag Enzyklopädie.

Kawashima, Atsuo, 1989. Textsorte und Partikeln im Japanischen und Deutschen. In: H. Weydt (ed.), Sprechen mit Partikeln. DeGruyter, Berlin, New York, 276-281.

König, Ekkehard, 1997. Zur Bedeutung von Modalpartikeln im Deutschen: Ein Neuansatz im Rahmen der Relevanztheorie. Germanistische Linguistik $136,57-75$.

König, Ekkehard, Requardt, Susanne, 1991. A relevance-theoretic approach to the analysis of modal particles in German. Multilingua 10, 1-2, 63-77.

König, Ekkehard and Stark, Detlef, 1991. The treatment of function words in a bilingual German-English dictionary. In: W. Abraham (ed.), Discourse Particles: Descriptive and Theoretical Investigations on the Logical, Syntactic, and Pragmatic Properties of Discourse Particles in German. John Benjamins, Amsterdam, 303-328.

Krivonosov, Alexej, 1963/1977. Die modalen Partikeln in der deutschen Gegenwartssprache. Alfred Kümmerle, Göppingen.

Krivonosov, Alexej, 1989. Zum Problem der Klassifizierung der deutschen Partikeln. In: H. Weydt (ed.), Sprechen mit Partikeln. DeGruyter, Berlin, New York, 30-38.

Lindner, Katrin, 1991. 'Wir sind ja doch alte Bekannte.' The use of German ja and doch as modal particles. In: W. Abraham (ed.), Discourse Particles: Descriptive and Theoretical Investigations on the Logical, Syntactic, and Pragmatic Properties of Discourse Particles in German. John Benjamins, Amsterdam, 303-328.

Nehls, Dietrich, 1989. German modal particles rendered by English auxiliary verbs. In: H. Weydt (ed.), Sprechen mit Partikeln. DeGruyter, Berlin, New York, 282-292.

Nemo, François, this volume. The Pragmatics of Common Ground. From Common Knowledge to Shared Attention and Social Referencing.

Nyan, Thanh, this volume. Common Ground, Categorization and Decision Making.

Okada, Moeko, this volume. Whose common ground? A misunderstanding caused by incorrect interpretatons of lexical markers of common ground.

O'Sullivan, Emer and Rösler, Dietmar, 1989. Wie kommen Abtönungspartikeln in deutsche Übersetzungen von Texten, deren Ausgangssprachen für diese keine direkten Äquivalente haben? In: H. Weydt (ed.), Sprechen mit Partikeln. DeGruyter, Berlin, New York, 204-216. 
Petric, Teodor, 1995. Indexikalische Leistungen der Partikeln und ihre natürlichkeitstheoretische Bewertung. Linguistica 35, 245-259.

Pickering, Martin J. and Garrod, Simon, 2004. Toward a mechanistic psychology of dialogue. Behavioral and Brain Sciences 27, 169-226.

Pittner, Karin, this volume. Common ground in interaction: the functions of medial doch in German.

Sacks, Harvey, Schegloff, Emanuel, Jefferson, Gail, 1974. A simplest systematics for the organization of turn-taking for conversation. Language 50, 4, 696735.

Sagerer, Gerhard, Rickheit, Gerd, Eikmeyer, Hans-Jürgen, 1994. Wir bauen jetzt ein Flugzeug. Materialband. SFB 360 „Situierte künstliche Kommunikatoren", University of Bielefeld.

Schegloff, Emanuel A., 1997. Whose Text, Whose Context? Discourse \& Society $8,2,165-187$.

Schubiger, Maria, 1965. English intonation and German modal particles: A comparative study. Phonetica 12, 65-84.

Sorjonen, Marja-Leena, 2001. Responding in Conversation. A Study of Response Particles in Finnish. Pragmatics \& Beyond New Series 70, John Benjamins, Amsterdam.

Sperber, Dan, Wilson, Deirdre, 1986. Relevance: Communication and Cognition. Blackwell, Oxford.

Thurmair, Maria, 1989. Modalpartikeln und ihre Kombinationen. Niemeyer, Tübingen.

Tannen, Deborah, 1979. What's in a Frame? Surface Evidence for Underlying Expectations. In: Freedle, Ron (ed.), New Directions in Discourse Processing. Ablex, Norwood, N.J, 137-181.

Thomason, Richmond H.,1992. Accommodation, meaning, and implicature: interdisciplinary foundations for pragmatics. In: Cohen, P.R. et al. (ed.), Intentions in Communication. MIT Press, Cambridge MA, 325-363.

Wahlster, Wolfgang, 2000(ed.). Verbmobil: Foundations of Speech-to-Speech Translation. Springer, Berlin etc..

Waltereit, Richard, 2001. Modal particles and their functional equivalents: a speech-act-theoretic approach. Journal of Pragmatics 33, 9, 1391-1417.

Weydt, Harald, 1986. Betonungsdubletten bei deutschen Partikeln. In: Weiss, W. et al. (eds.), Textlinguistik contra Stilistik? Wortschatz und Wörterbuch. Tübingen, 393-403.

Weydt, Harald, 2005. What are particles good for? In: Fischer, K. (ed.), Approaches to Discourse Particles. Elsevier, Amsterdam.

Wierzbicka, Anna, 1990. 'Prototypes save': on the uses and abuses of the notion 'prototype' in linguistics and related fields. In: Tsohatzidis, Savas L. (ed.), Meanings and Prototypes. Studies in Linguistic Categorization. London, 
347-367. 